\title{
Gender disparity in the prescription of secondary prevention medications in a Malaysian primary care clinic
}

\author{
Noorhida Baharudin, Ahmad Muslim Ahmad Roslan, Mohamed Syarif Mohamed Yassin, \\ Anis Safura Ramli, Aiza Nur Izdihar Zainal Abidin, Nurul Hidayatullaila Sahar, Nor Shazatul \\ Salwana Din, Izyana Syazlin Ibrahim, Siti Nur Hidayah Abd Rahim, Nur Athirah Rosli \\ Baharudin N, Ahmad-Roslan AM, Mohamed-Yassin MS, et al. Gender disparity in the prescription of secondary prevention medications in a \\ Malaysian primary care clinic. Malays Fam Physician. 2021;16(2);37-44. https://doi.org/10.51866/oa1080
}

\section{Keywords:}

Secondary prevention

medications, gender disparity,

primary care, Malaysia

\section{Authors:}

\section{Noorhida Baharudin \\ (Corresponding author) \\ MBBS (Monash), FRACGP (Australia) \\ Department of Primary Care \\ Medicine, Faculty of Medicine \\ Universiti Teknologi MARA, Selayang \\ Campus, Selangor, Malaysia \\ Email: noorhida@yahoo.com}

Ahmad Muslim Ahmad Roslan

MBBS (RCMP)

Department of Primary Care

Medicine, Faculty of Medicine

Universiti Teknologi MARA, Selayang

Campus, Selangor, Malaysia

\section{Mohamed Syarif Mohamed}

Yassin

MBBS (Monash), FRACGP (Australia)

Department of Primary Care

Medicine, Faculty of Medicine

Universiti Teknologi MARA, Selayang

Campus, Selangor, Malaysia

\begin{abstract}
Introduction: Cardiovascular disease is the leading cause of death worldwide. Despite the proven benefit of secondary prevention medications (SPMs), their utilisation remains suboptimal in many countries. This study aimed to assess the use of SPMs in a Malaysian primary care clinic and factors associated with it.

Methods: A retrospective review of electronic medical records was conducted to assess the prescription of SPMs among patients with coronary artery disease who attended the clinic between 1st January 2018 and 31st December 2018. Prescriptions of SPMs were documented in numbers and percentages. Multiple logistic regressions were used to analyse factors associated with the prescription of SPMs.

Results: Of the 662 patients included in the study, 99.1\% were prescribed statins, 97\% antiplatelets, $81.7 \%$ angiotensin-converting enzyme (ACE)-inhibitors or angiotensin II receptor blockers (ARBs), and $78.7 \%$ beta-blockers. Male patients were more likely to be prescribed statins $(\mathrm{OR}=8.584,95 \% \mathrm{CI}: 1.431-51.510)$ and antiplatelets (OR = 6.818, 95\% CI: 2.294 - 20.257). Another significant factor for antiplatelets prescription was having diabetes $(\mathrm{OR}=3.318,95 \% \mathrm{CI}$ : $1.148-9.590)$. Having hypertension was associated with ACE-inhibitors or ARBs prescription $(\mathrm{OR}=4.008,95 \%$ CI: $2.522-6.370)$.

Conclusion: Although the majority of patients received SPMs, there were significant disparities for some SPMs prescriptions among female patients. As these medications are widely available in the Malaysian primary care setting, steps should be taken to ensure that these medications are prescribed equally for all eligible patients.
\end{abstract}

\section{Introduction}

Cardiovascular disease (CVD) is the world's leading cause of death. ${ }^{1}$ Approximately 17.9 million people die from CVD each yearapproximately $31 \%$ of all deaths worldwide. ${ }^{1}$ Furthermore, more than $75 \%$ of CVD deaths occur in low and medium-income countries, and $85 \%$ of all CVD deaths are due to heart attacks and stroke. ${ }^{1}$

In Malaysia, ischaemic heart disease (IHD) remains the leading cause of death at $13.9 \% .^{2}$ Death secondary to IHD among males has been increasing recently, from $15.3 \%$ in 2016 to $16 \%$ in 2017 , and this pattern has also been observed among females. ${ }^{2}$

Nearly half of Malaysian adults have a clustering of CVD risk factors such as smoking, obesity, hypercholesterolemia, hypertension and diabetes, with $43.2 \%$ of adults having at least two of these risk factors. ${ }^{3,4}$ According to the INTERHEART study, these risk factors, together with abdominal obesity, psychological stressors, poor dietary habits and lack of exercise, have contributed to more than $90 \%$ of initial myocardial infarctions. ${ }^{5}$

The reduction of CVD risk factors and subsequent CVD mortality can be achieved through improved treatment strategies, including non-pharmacotherapy management, pharmacotherapy management and intensive control of individual risk factors. ${ }^{3}$ Among these strategies, overwhelming evidence has demonstrated the effectiveness of secondary prevention medications (SPMs) for reducing CVD events and mortality. ${ }^{6,7}$ Despite this, 


\author{
Anis Safura Ramli \\ MBBS (Newcastle, UK), MRCGP (UK) \\ Department of Primary Care \\ Medicine, Faculty of Medicine \\ Universiti Teknologi MARA, Selayang \\ Campus, Selangor, Malaysia \\ Institute of Pathology, Laboratory \\ and Forensic Medicine (I-PPerForM) \\ Universiti Teknologi MARA, Sungai \\ Buloh Campus, Selangor, Malaysia

\section{Aiza Nur Izdihar Zainal Abidin \\ MD (Volgograd, Russia) \\ Department of Primary Care \\ Medicine, Faculty of Medicine, \\ Universiti Teknologi MARA, Selayang} \\ Campus, Selangor, Malaysia
}

\section{Nurul Hidayatullaila Sahar}

MB. BCh. BAO (TCD, Ireland)

Department of Primary Care

Medicine, Faculty of Medicine,

Universiti Teknologi MARA, Selayang

Campus, Selangor, Malaysia

\section{Nor Shazatul Salwana Din \\ MD (UKM)}

Department of Primary Care

Medicine, Faculty of Medicine,

Universiti Teknologi MARA, Selayang

Campus, Selangor, Malaysia

Izyana Syazlin Ibrahim

MD (USU, Indonesia)

Department of Primary Care

Medicine, Faculty of Medicine,

Universiti Teknologi MARA, Selayang

Campus, Selangor, Malaysia

\section{Siti Nur Hidayah Abd Rahim}

MBBS (IMU)

Department of Primary Care

Medicine, Faculty of Medicine,

Universiti Teknologi MARA, Selayang

Campus, Selangor, Malaysia

\section{Nur Athirah Rosli}

MBBS (UiTM)

Department of Primary Care

Medicine, Faculty of Medicine,

Universiti Teknologi MARA, Selayang

Campus, Selangor, Malaysia the utilisation of these medications remains suboptimal worldwide, especially in lowincome countries. ${ }^{8}$

Various factors contribute to low utilisation of SPMs, such as socioeconomic status, access to healthcare and patient-level barriers like medication adherence. ${ }^{9}$ Several studies have found that patients' demographic characteristics, such as gender and age, are significant determinants for prescription of SPMs. ${ }^{10-13}$

In Malaysia, Kassab et al. discovered that although utilisation of SPMs was generally good among patients discharged from hospital following acute coronary syndrome, older patients are less likely to be prescribed SPMs. ${ }^{14}$ Furthermore, the extent to which SPMs is prescribed among patients in a primary care setting remains unknown. This study therefore aimed to ascertain whether prescriptions of SPMs in the primary care clinic are in line with the Malaysian Primary and Secondary Prevention of Cardiovascular Disease and Stable Coronary Artery Disease guidelines.,15 This study also aimed to assess the factors associated with prescription of SPMs among these patients.

\section{Materials and Methods \\ Study design and population}

This study was conducted at a university primary care clinic in Selangor, Malaysia. A retrospective review of electronic medical records (EMR) was performed for patients with coronary artery disease (CAD) who attended the clinic between 1st January 2018 and 31st December 2018. A list of patients who attended the clinic during the study period was obtained from the clinic's information technology (IT) unit, and those patients were screened for eligibility. Patients with $\mathrm{CAD}$ who were older than 18 years of age and attended the clinic at least once for their CAD follow up were included in the study. The exclusion criteria were patients who were pregnant or who followed up at other clinics after attending our clinic for acute care or prescriptions only. CAD was defined as previous acute coronary syndrome (unstable angina, myocardial infarction) that required referral or admission to hospital, or established CAD confirmed through diagnostic cardiac procedures, such as coronary angiography, cardiac computed tomography scan, cardiac magnetic resonance imaging, echocardiography or an exercise stress test.

\section{Sample size determination}

A study conducted by Kassab et al. found that $95.7 \%$ of patients were prescribed antiplatelets, $80.3 \%$ beta-blockers, $95 \%$ statins and $69.7 \%$ angiotensin-converting enzyme (ACE)-inhibitors or angiotensin II receptor blockers (ARBs). ${ }^{14}$ Based on this, using a single proportion formula and taking the $\alpha$ value of 0.05 with an absolute precision of $5 \%$, the minimum calculated sample sizes were 64, 244, 73 and 325, respectively. To ensure adequate sample size for logistic regression, Bujang et al. recommended a minimum sample size of 500 or the formula $\mathrm{n}=100+$ $50 i$, where $i$ is the number of independent variables in the final model. ${ }^{16}$ This study proposed to include seven independent variables, therefore using this formula, the total minimum sample size required was 500 . Overall, based on these calculation methods, this study aimed to sample a minimum of 500 patients.

\section{Study procedure}

The institution's permission to access the EMR was obtained prior to conducting the study. The list of patients who attended the clinic during the study period was gathered from the clinic's IT unit. The data were extracted in two stages. First, the data were extracted by visits and later they were sorted by patients' medical reference numbers to prevent duplicates. Based on the list, the patients were screened for eligibility. The clinic does not have a CAD registry, so systematic random sampling could not be performed. To minimise sampling bias, a consecutive sampling method was used until the target sample size was achieved.

The demographic and clinical details of the eligible patients were extracted from the EMR by the investigators, who were trained prior to data collection to ensure standardisation. The data were documented on a standardised data collection sheet that included demographic characteristics such as age, gender and ethnicity, as well as clinical data such as smoking status, Type 1 or 2 diabetes mellitus (DM), hypertension and dyslipidaemia history. The outcomes of this study were the prescriptions of four SPMs (statins, antiplatelets, ACE-inhibitors or ARBs, and beta-blockers). The four SPMs were chosen based on the Malaysian Clinical Practice Guidelines of Stable Coronary Artery Disease, which recommended these medications for patients with stable CAD, if appropriate. ${ }^{15}$ DM, hypertension and dyslipidaemia 
were defined as a clinician's diagnosis of DM, hypertension or dyslipidaemia, and/ or if the patient was taking at least one oral hypoglycaemic agent, antihypertensive agent or lipid-lowering agent. Smoking status was defined as current smoking status at the time of the study, as documented in the EMR. Other information collected included main treating physician (family medicine specialist, cardiologist or medical officer) and clinical history precluding patients from being prescribed SPMs, such as clinician's diagnosis of asthma, chronic obstructive pulmonary disease (COPD), dyspepsia, gastritis or peptic (gastric and/or duodenal) ulcer diseases.

\section{Statistical Analysis}

Data entry and statistical analysis were performed using IBM SPSS Statistics for Windows, Version 26. ${ }^{17}$ The descriptive analyses were expressed as mean with standard deviation (SD) or median with interquartile range (IQR) for normally distributed and non-normally distributed data, respectively. Categorical variables were described in numbers and percentages. Multivariate analysis using logistic regression with enter method was performed to assess the factors associated with prescription of SPMs. The demographic factors (age, race, gender) and clinical factors (treating doctor, diabetes, hypertension, dyslipidaemia) were the independent variables. For smoking status, $47.7 \%$ of the data was missing, so it was omitted as an independent variable in the logistic regression analysis. The dependent variables were prescriptions of the four SPMs: antiplatelets, statins, ACE-inhibitors or ARBs, and beta-blockers.

Four separate logistic regression analyses were conducted for factors associated with prescription of antiplatelets, statins, ACEinhibitors or ARBs, and beta-blockers. The overall model fitness was assessed using the Hosmer-Lemeshow goodness-of-fit test and the receiver operating characteristic (ROC) curve. The Hosmer-Lemeshow goodness-offit tests for all four models were insignificant ( $\mathrm{p}$-values $0.302-0.888$ ), indicating the models fit the data well.

All four models explained 3.6 - 22.9\% (Nagelkerke $\mathrm{R}$ Square) of the variance in the prescription of SPMs, and were able to discriminate $60.5 \%(\mathrm{ROC}=60.5 \%, 95 \%$ CI: $0.554-0.656, p<0.05)$ to $89.0 \%$
(ROC $=89.0 \%, 95 \%$ CI: $0.796-0.983, \mathrm{p}<$ 0.05 ) of patients being prescribed or not being prescribed SPMs.

Results are presented as odds ratios (OR) with 95\% confidence intervals (CI), and a p-value < 0.05 was considered statistically significant.

\section{Results}

\section{Patient characteristics}

A total of 662 eligible patients were identified from the EMR; their demographic and clinical characteristics are presented in Table 1. The mean $( \pm \mathrm{SD})$ age of patients was 63 years $( \pm 9.8)$. The patients were predominantly male $(81.4 \%)$ and of Malay ethnicity $(66.2 \%)$. The majority of patients had cardiovascular risk factors such as DM (55.4\%), hypertension (80.5\%) and dyslipidaemia (66.3\%). As the data were retrieved from the EMR, some information was not available, such as smoking status and duration since quitting smoking for ex-smokers.

\section{Prescription of secondary prevention medications}

The proportions of patients being prescribed SPMs are illustrated in Table 2. Patients who were diagnosed with dyspepsia/gastritis/peptic ulcers and/or asthma/COPD were excluded from analyses for antiplatelet and beta-blocker prescriptions, respectively. Among the SPMs, the most commonly prescribed were statins (99.1\%), followed by antiplatelets (97\%), ACE-inhibitors/ARBs (81.7\%) and betablockers (78.7\%).

\section{Factors associated with prescription of secondary prevention medications}

The factors associated with prescription of SPMs among patients with CAD are shown in Table 3. Male patients were nearly seven times more likely to be prescribed antiplatelets $(\mathrm{OR}=6.818,95 \% \mathrm{CI}: 2.294-20.257)$ and eight times more likely to be prescribed statins $(\mathrm{OR}=8.584,95 \% \mathrm{CI}: 1.431-51.510)$ when compared to females. In addition, patients with diabetes were also more likely to be prescribed antiplatelets $(\mathrm{OR}=3.318,95 \%$ CI: 1.148 - 9.590). As expected, hypertensive patients were four times more likely to be prescribed ACE-inhibitors or ARBs (OR = 4.008, 95\% CI: $2.522-6.370)$ than were patients without hypertension. 
Table 1. Demographic and clinical characteristics of patients with coronary artery disease, $n=662$

\begin{tabular}{|l|l|l}
\hline Variables & Frequency, n (\%) & Mean ( \pm SD) \\
\hline
\end{tabular}

All patients

Age (years)

$662(100)$

$\begin{array}{lc}\text { Age }(\text { years }) & \\ <30 \text { years old } & 1(0.2) \\ 30-39 \text { years old } & 4(0.6) \\ 40-49 \text { years old } & 53(8.0) \\ 50-59 \text { years old } & 179(27.0) \\ \geq 60 \text { years old } & 425(64.2)\end{array}$

Gender

Female

Male

$123(18.6)$

$539(81.4)$

Race

Malay $438(66.2)$

Chinese $162(24.5)$

Indian $\quad 60(9.1)$

Others $2(0.3)$

Smoking Status

Smoker $242(36.6)$

Non-smoker/ex-smoker $104(15.7)$

Unknown $316(47.7)$

Comorbidities

Type 1 or 2 diabetes mellitus $\quad 367(55.4)$

Hypertension $533(80.5)$

Dyslipidaemia $439(66.3)$

Asthma or chronic obstructive pulmonary disease 39 (5.9)

Dyspepsia/gastritis/peptic ulcers $93(14)$

Treating doctor

Specialist (cardiologist or family medicine specialist) 241 (36.4)

Medical officer

$421(63.6)$

Table 2. Prescription of secondary prevention medications to patients with coronary artery disease

\begin{tabular}{lcccc} 
& $\begin{array}{c}\text { Antiplatelets*, } \\
\text { n (\%) }\end{array}$ & $\begin{array}{c}\text { Statins+, } \\
\text { n (\%) }\end{array}$ & $\begin{array}{c}\text { ACE-inhibitors } \\
\text { or ARBs+, n (\%) }\end{array}$ & $\begin{array}{c}\text { Beta-blockers^, } \\
\text { n (\%) }\end{array}$ \\
\hline Prescribed & $552(97)$ & $656(99.1)$ & $541(81.7)$ & $490(78.7)$ \\
\hline Not prescribed & $17(3)$ & $6(0.9)$ & $121(18.3)$ & $133(21.3)$
\end{tabular}

\section{Notes}

* excluded patients with dyspepsia/gastritis/peptic ulcers, $\mathrm{n}=569$

+ included all patients, $\mathrm{n}=662$

$\wedge$ excluded patients with asthma or COPD, $n=623$

$\mathrm{ACE}=$ angiotensin-converting enzyme

$\mathrm{ARBs}=$ angiotensin II receptor blockers 
Table 3. Factors associated with prescription of secondary prevention medications to patients with coronary artery disease

\begin{tabular}{|c|c|c|c|c|c|c|c|c|}
\hline \multirow{2}{*}{ Variables } & \multicolumn{2}{|c|}{ Antiplatelets* } & \multicolumn{2}{|l|}{ Statins+ } & \multicolumn{2}{|c|}{ ACE-inhibitors or ARBs+ } & \multicolumn{2}{|c|}{ 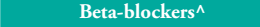 } \\
\hline & OR $(95 \% \mathrm{CI})$ & p-value & OR $(95 \% \mathrm{CI})$ & p-value & OR $(95 \% \mathrm{CI})$ & p-value & OR $(95 \% \mathrm{CI})$ & p-value \\
\hline \multicolumn{9}{|l|}{ Age } \\
\hline$<60$ years old & 1 & Ref & 1 & Ref & 1 & Ref & 1 & Ref \\
\hline$\geq 60$ years old & $1.533(0.511-4.593)$ & 0.446 & $1.310(0.204-8.417)$ & 0.776 & $0.868(0.559-1.347)$ & 0.527 & $0.715(0.469-1.091)$ & 0.120 \\
\hline \multicolumn{9}{|l|}{ Gender } \\
\hline Female & 1 & Ref & 1 & Ref & 1 & Ref & 1 & Ref \\
\hline Male & $6.818(2.294-20.257)$ & 0.001 & $8.584(1.431-51.510)$ & 0.019 & $0.996(0.568-1.748)$ & 0.990 & $1.321(0.810-2.153)$ & 0.264 \\
\hline \multicolumn{9}{|l|}{ Race } \\
\hline Non-Malay & 1 & Ref & 1 & Ref & 1 & Ref & 1 & Ref \\
\hline Malay & $1.854(0.677-5.071)$ & 0.229 & $8.197(0.931-72.192)$ & 0.058 & $0.953(0.615-1.476)$ & 0.830 & $0.968(0.641-1.462)$ & 0.877 \\
\hline \multicolumn{9}{|l|}{ Treating doctor } \\
\hline Medical officer & 1 & Ref & 1 & Ref & 1 & Ref & 1 & Ref \\
\hline Specialist & $0.999(0.350-2.854)$ & 0.999 & $0.328(0.057-1.884)$ & 0.221 & $1.111(0.718-1.718)$ & 0.637 & $1.516(0.996-2.309$ & 0.052 \\
\hline (cardiologist or & & & & & & & & \\
\hline family medicine & & & & & & & & \\
\hline specialist) & & & & & & & & \\
\hline \multicolumn{9}{|l|}{ Dyslipidaemia } \\
\hline No & 1 & Ref & 1 & Ref & 1 & Ref & 1 & Ref \\
\hline Yes & $0.413(0.110-1.550)$ & 0.190 & $2.226(0.376-13.174)$ & 0.378 & $0.926(0.597-1.437)$ & 0.732 & $0.616(0.396-0.957)$ & 0.031 \\
\hline \multicolumn{9}{|l|}{ Diabetes } \\
\hline No & 1 & Ref & 1 & Ref & 1 & Ref & 1 & Ref \\
\hline Yes & $3.318(1.148-9.590)$ & 0.027 & $0.797(0.124-5.111)$ & 0.811 & $1.407(0.924-2.142)$ & 0.111 & $1.128(0.758-1.677)$ & 0.553 \\
\hline \multicolumn{9}{|l|}{ Hypertension } \\
\hline No & 1 & Ref & 1 & Ref & 1 & Ref & 1 & Ref \\
\hline Yes & $0.762(0.153-3.809)$ & 0.741 & $0.943(0.078-11.370)$ & 0.963 & $4.008(2.522-6.370)$ & $<0.005$ & $1.566(0.957-2.562)$ & 0.074 \\
\hline
\end{tabular}

\section{Notes}

* excluded patients with dyspepsia/gastritis/peptic ulcers, $\mathrm{n}=569$

+ included all patients, $\mathrm{n}=662$

$\wedge$ excluded patients with asthma or COPD, $\mathrm{n}=623$

No multicollinearity

Factors analysed: age, race, gender, treating doctor, diabetes, hypertension and dyslipidaemia $\mathrm{ACE}=$ angiotensin-converting enzyme $\mathrm{ARBs}=$ angiotensin II receptor blockers

\section{Discussion}

This study demonstrated good pharmacotherapy management for patients with $\mathrm{CAD}$ in this primary care clinic. The majority of patients from this study received SPMs, ranging from $78.7 \%$ receiving betablockers to $99.1 \%$ receiving statins. Our findings were encouraging and comparable to a Malaysian study conducted in secondary care where $80.3 \%$ of patients received beta-blockers and $98.2 \%$ received statins upon discharge. ${ }^{14}$ The level of adherence among patients was lower at the two-year follow up, however. ${ }^{18}$ In contrast, Yusuf et al. reported much lower utilisation of SPMs in some communities in Malaysia. Among 289 patients with selfreported CAD, less than 20\% received SPMs. ${ }^{8}$

International studies looking at the prescription of SPMs at the community level have yielded varying results. An audit conducted at a primary care setting in the United Kingdom showed that $98.4 \%$ of patients with CAD were prescribed antiplatelet therapy in the community, which is comparable to our findings. ${ }^{19}$ A study from Spain demonstrated that 37.7 - 85\% of their patients received SPMs. ${ }^{10}$ Larger community-based studies have demonstrated a smaller proportion of SPMs use in study populations. ${ }^{8,20}$ Among patients with CAD, $20.4-73.6 \%$ of patients in Europe and North America received SPMs, with smaller percentages in the Middle East, South America and Asia. ${ }^{8}$ Chen et al. reported much lower utilisation of SPMs in China, ranging from $1.4 \%$ to $12.3 \% .^{20}$

Concerning factors associated with the prescription of SPMs, this study found that male gender was a significant factor, specifically for antiplatelets and statins therapy. Many studies have discovered similar outcomes. ${ }^{11,12,21,22}$ Recent literature has debated whether this is due to gender disparity for treatment initiation, or adherence issues among women. Smolina et al. found the former to be the factor contributing to suboptimal SPMs therapy among women, especially those younger than 55 years of age. $^{12}$ Magee et al., however, concluded that apart from antiplatelet therapy, women were being treated as aggressively as men. ${ }^{23}$ Despite this, blood pressure and lipid control 
among these women remained suboptimal. Biological factors and treatment adherence were among the reasons proposed to contribute to this. ${ }^{23}$ In addition, women were more likely to discontinue statin therapy due to side effects such as muscle pain, as well as feeling dissatisfied with the consultation with their clinicians regarding statin therapy. ${ }^{24}$ Despite having a lower prevalence of obstructive CAD from angiography, one study found that more women than men died from CAD and women were more likely to die from cardiac arrest prior to arriving at the hospital, in comparison to men. ${ }^{25}$ Furthermore, women also experienced poorer quality of life and more adverse outcomes related to CAD. ${ }^{25}$ Current evidence indicates that SPMs therapy, particularly statins, is as efficacious among men as it is among women for prevention of major vascular events. ${ }^{26}$ Thus, treatment with SPMs should be appropriately and fairly prescribed for all women with CAD. ${ }^{26}$ Patient factors such as medication adherence require intensive, multifaceted strategies for improvement, and are difficult to achieve. ${ }^{27}$ Under-prescription by doctors should therefore be avoided to ensure optimal evidence-based care for patients in primary care, especially when SPMs is widely available.

\section{Strengths, limitations and implications for future research and clinical practice}

To the best of our knowledge, this is the first study assessing the factors associated with SPMs prescription in the Malaysian primary care setting. The findings address the gap in the literature and provide useful insight for primary care providers. This study does, however, have some limitations. Firstly, this is a single-centre study where the medical officers were pursuing postgraduate qualification in primary care medicine. Their medical knowledge and skills might be better compared to medical officers who are not pursuing postgraduate training in primary care. Hence, this study may not be representative of all medical officers serving primary care in Malaysia. Secondly, the majority of the patients in this study were Malays, so other ethnic groups in Malaysia, such as Chinese and Indians, were underrepresented. For this reason, the results may not be generalisable to other primary care clinics in Malaysia. Future research should include a larger, multi-centre study to improve the generalisability of the results. Finally, some factors that may affect the usage of SPMs, such as patients' attitudes and beliefs towards SPMs use, as well as the socioeconomic status of the patients, were not available in the EMR and so were not explored in this study. The results from the multiple logistic regressions must therefore be interpreted with care. Future studies should include other factors that may affect the prescription of SPMs, as well as assessing adherence to SPMs among patients with $\mathrm{CAD}$ in primary care. In terms of clinical implications, the findings of this study will provide useful insights with which medical doctors can examine their own prescription practice to ensure that female patients are being prescribed SPMs fairly, as indicated. As for strategies for improvement, the findings of this study may be used to develop teaching materials for doctors' continuing professional development, which could help address potential gaps in knowledge, improving prescribing practice and, ultimately, patient care.

\section{Conclusion}

In conclusion, the majority of patients with CAD in this study received SPMs, but underutilisation of some of these medications was still observed among female patients. Given that SPMs is widely available in primary care, under-prescription of these medications by doctors should be avoided to ensure patients receive the best evidence-based treatment.

\section{Acknowledgments}

We would like to thank the Deputy Dean of Clinical Services, Faculty of Medicine, UiTM for his permission to access electronic medical records for the purpose of this study. We would like to show appreciation to Dr Mohamad Rodi Isa, from the Department of Population Health and Preventive Medicine, Faculty of Medicine, UiTM for his advice on statistical analysis. We would also like to thank the staff at the Primary Care Specialist Clinic, UiTM for their support throughout data collection.

\section{Author's contributions}

Baharudin N, Ahmad-Roslan AM, Zainal ANI, Sahar NH, Din NSS, Ibrahim IS, Rahim SNHA and Rosli NA designed the study and acquired the data. Baharudin $\mathrm{N}$ and Mohamed-Yassin MS analysed and interpreted the data. Baharudin N, Mohamed-Yassin MS and Ramli AS drafted and critically revised the manuscript. All authors reviewed and approved the final manuscript.

\section{Funding sources}

This study was not funded by any grant from any public, commercial or not-for-profit sectors. 


\section{Conflicts of interest}

The authors declare no conflicts of interest.

\section{Ethics approval}

This study was approved by the institutional Ethics Committee of Universiti Teknologi MARA (UiTM) [(600-IRMI $(5 / 1 / 6)$ REC/349/19].

\section{How does this paper make a difference to general practice?}

- This study provides useful insights for primary care doctors regarding the prescription of SPMs in a primary care clinic and factors associated with it.

- This study demonstrated gender disparities for antiplatelet and statin prescriptions among patients with CAD.

- The benefits of statins and antiplatelets are well-established for both genders. Primary care providers in Malaysia must therefore ensure that these medications are prescribed to both males and females appropriately, in the absence of contraindication.

\section{References}

1. World Health Organization. Cardiovascular diseases (CVDs) 2017 [accessed 05 February 2020]. Available from: https://www.who. int/en/news-room/fact-sheets/detail/ cardiovascular-diseases-(cvds).

2. Department of Statistics Malaysia. Statistics on causes of death Malaysia 2018 [accessed 05 February 2020]. Available from: http://bit. ly/2ZteJYn.

3. Ministry of Health Malaysia. Clinical practice guidelines on primary \& secondary prevention of cardiovascular disease 2017. Available from: http://www.acadmed.org.my/.

4. Nuur Amalina AG, Jamaiyah H, Selvarajah S, et al. Geographical variation of cardiovascular risk factors in Malaysia. Med J Malaysia. 2012;67(1):31-8. Epub 2012/05/16. PubMed PMID: 22582546.

5. Yusuf S, Hawken S, Ounpuu S, et al. Effect of potentially modifiable risk factors associated with myocardial infarction in 52 countries (the INTERHEART study): Case-control study. Lancet. 2004;364(9438):937-52. Epub 2004/09/15. doi: 10.1016/S01406736(04)17018-9. PubMed PMID: 15364185 .
6. Ma TT, Wong ICK, Man KKC, et al. Effect of evidence-based therapy for secondary prevention of cardiovascular disease: Systematic review and metaanalysis. PLoS One. 2019;14(1):e210988. Epub 2019/01/19. doi: 10.1371/ journal.pone.0210988. PubMed PMID: 30657781; PubMed Central PMCID: PMCPMC6338367.

7. Thompson AM, Hu T, Eshelbrenner CL, et al. Antihypertensive treatment and secondary prevention of cardiovascular disease events among persons without hypertension: A metaanalysis. JAMA. 2011;305(9):913-22. Epub 2011/03/03. doi: 10.1001/jama.2011.250. PubMed PMID: 21364140; PubMed Central PMCID: PMCPMC4313888.

8. Yusuf S, Islam S, Chow CK, et al. Use of secondary prevention drugs for cardiovascular disease in the community in high-income, middle-income, and lowincome countries (the PURE Study): A prospective epidemiological survey. Lancet. 2011;378(9798):1231-43. Epub 2011/08/30. doi: 10.1016/S0140-6736(11)61215-4. PubMed PMID: 21872920.
9. Murphy A, Palafox B, O’Donnell O, et al. Inequalities in the use of secondary prevention of cardiovascular disease by socioeconomic status: Evidence from the PURE observational study. Lancet Glob Health. 2018;6(3):e292-e301. Epub 2018/02/13. doi: 10.1016/S2214-109X(18)30031-7. PubMed PMID: 29433667; PubMed Central PMCID PMCPMC5905400.

10. Turon JM, Librero J, Diaz GJ, et al. Auditing secondary prevention of ischaemic heart disease in rural areas of Spain: An opportunity for improvement. Eur J Gen Pract. 2006;12(4):156-62. Epub 2006/11/28. doi: 10.1080/13814780601009786. PubMed PMID: 17127601 .

11. Rosenson RS, Farkouh ME, Mefford M, et al. Trends in use of high-intensity statin therapy after myocardial infarction, 2011 to 2014. J Am Coll Cardiol. 2017;69(22):2696706. Epub 2017/06/03. doi: 10.1016/j. jacc.2017.03.585. PubMed PMID: 28571633

12. Smolina K, Ball L, Humphries KH, et al. Sex disparities in post-acute myocardial infarction pharmacologic treatment initiation and adherence: Problem for young women. Circ Cardiovasc Qual Outcomes. 2015;8(6):58692. Epub 2015/10/16. doi: 10.1161/ CIRCOUTCOMES.115.001987. PubMed PMID: 26462876. 
13. Gunnell AS, Hung J, Knuiman MW, et al. Secondary preventive medication use in a prevalent population-based cohort of acute coronary syndrome survivors. Cardiovasc Ther. 2016;34(6):423-30. Epub 2016/08/05. doi: 10.1111/1755-5922.12212. PubMed PMID: 27489053.

14. Kassab YW, Hassan Y, Aziz NA, et al. Use of evidence-based therapy for the secondary prevention of acute coronary syndromes in Malaysian practice. J Eval Clin Pract. 2013;19(4):658-63. Epub 2012/08/01. doi: 10.1111/j.1365-2753.2012.01894.x. PubMed PMID: 22845427.

15. Clinical Practice Guidelines of Stable Coronary Artery Disease 2018. Kuala Lumpur: National Heart Association of Malaysia; 2018 [accessed 2020. Available from: http://www.acadmed.org.my/.

16. Bujang MA, Sa'at N, Sidik T, et al. Sample size guidelines for logistic regression from observational studies with large population: Emphasis on the accuracy between statistics and parameters based on real life clinical data. Malays J Med Sci. 2018;25(4):12230. Epub 2019/03/28. doi: 10.21315/ mjms2018.25.4.12. PubMed PMID: 30914854; PubMed Central PMCID: PMCPMC6422534.

17. IBM SPSS Statistics for Windows. $26 \mathrm{ed}$. Armonk, NY: IBM Corp; 2019.

18. Kassab YW, Hassan Y, Aziz NA, et al. Report: Trends in adherence to secondary prevention medications in post-acute coronary syndrome patients. Pak J Pharm Sci. 2015;28(2):6416. Epub 2015/03/03. PubMed PMID: 25730796

19. Dunkley A, Stone M, Squire I, et al. An audit of secondary prevention of coronary heart disease in post acute myocardial infarction patients in primary care. Quality in Primary Care. 2006;14:15-20.
20. Chen Y, Li L, Zhang Q, et al. Use of drug treatment for secondary prevention of cardiovascular disease in urban and rural communities of China: China Kadoorie Biobank Study of 0.5 million people. Int J Cardiol. 2014;172(1):8895. Epub 2014/01/28. doi: 10.1016/j. ijcard.2013.12.065. PubMed PMID: 24461961; PubMed Central PMCID: PMCPMC3991854.

21. Pereira M, Araujo C, Dias P, et al. Age and sex inequalities in the prescription of evidencebased pharmacological therapy following an acute coronary syndrome in Portugal: The EURHOBOP study. Eur J Prev Cardiol. 2014;21(11):1401-8. Epub 2013/06/22. doi: $10.1177 / 2047487313494580$. PubMed PMID: 23787795.

22. Jorgensen $\mathrm{CH}$, Gislason $\mathrm{GH}$, Ahlehoff $\mathrm{O}$, et al. Use of secondary prevention pharmacotherapy after first myocardial infarction in patients with diabetes mellitus. BMC Cardiovasc Disord. 2014;14:4. Epub 2014/01/11. doi: 10.1186/1471-2261-14-4. PubMed PMID: 24406095; PubMed Central PMCID: PMCPMC3897983.

23. Magee MF, Tamis-Holland JE, Lu J, et al. Sex, prescribing practices and guideline recommended, blood pressure, and LDL cholesterol targets at baseline in the BARI 2D trial. Int J Endocrinol. 2015;2015:610239. Epub 2015/04/16. doi 10.1155/2015/610239. PubMed PMID: 25873955; PubMed Central PMCID: PMCPMC4383496.

24. Karalis DG, Wild RA, Maki KC, et al. Gender differences in side effects and attitudes regarding statin use in the Understanding Statin Use in America and Gaps in Patient Education (USAGE) study. J Clin Lipidol. 2016;10(4):833-41. Epub 2016/09/01. doi: 10.1016/j.jacl.2016.02.016. PubMed PMID: 27578114.
25. Shaw LJ, Bairey Merz CN, Pepine CJ, et al Insights from the NHLBI-sponsored Women's Ischemia Syndrome Evaluation (WISE) study: Part I: Gender differences in traditional and novel risk factors, symptom evaluation, and gender-optimized diagnostic strategies. $\mathrm{J} \mathrm{Am}$ Coll Cardiol. 2006;47(3 Suppl):S4-S20. Epub 2006/02/07. doi: 10.1016/j.jacc.2005.01.072. PubMed PMID: 16458170.

26. Fulcher J, O’Connell R, Voysey M, et al. Efficacy and safety of LDL-lowering therapy among men and women: Metaanalysis of individual data from 174,000 participants in 27 randomised trials. Lancet. 2015;385(9976):1397-405. Epub 2015/01/13. doi: 10.1016/s01406736(14)61368-4. PubMed PMID: 25579834

27. Kini V, Ho PM. Interventions to improve medication adherence: A review. JAMA. 2018;320(23):2461-73. Epub 2018/12/19. doi: 10.1001/jama.2018.19271. PubMed PMID: 30561486. 